\title{
Downregulation of FAP suppresses cell proliferation and metastasis through PTEN/PI3K/AKT and Ras-ERK signaling in oral squamous cell carcinoma
}

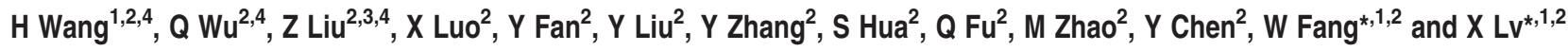

It is largely recognized that fibroblast activation protein (FAP) is expressed in cancer-associated fibroblasts (CAFs) of many human carcinomas. Furthermore, FAP was recently also reported to be expressed in carcinoma cells of the breast, stomach, pancreatic ductal adenocarcinoma, colorectum, and uterine cervix. The carcinoma cell expression pattern of FAP has been described in several types of cancers, but the role of FAP in oral squamous cell carcinoma (OSCC) is unknown. The role of endogenous FAP in epithelium-derived tumors and molecular mechanisms has also not been reported. In this study, FAP was found to be expressed in carcinoma cells of OSCC and was upregulated in OSCC tissue samples compared with benign tissue samples using immunohistochemistry. In addition, its expression level was closely correlated with overall survival of patients with OSCC. Silencing FAP inhibited the growth and metastasis of OSCC cells in vitro and in vivo. Mechanistically, knockdown of FAP inactivated PTEN/PI3K/AKT and Ras-ERK and its downstream signaling regulating proliferation, migration, and invasion in OSCC cells, as the inhibitory effects of FAP on the proliferation and metastasis could be rescued by PTEN silencing. Our study suggests that FAP acts as an oncogene and may be a potential therapeutic target for patients with OSCC.

Cell Death and Disease (2014) 5, e1155; doi:10.1038/cddis.2014.122; published online 10 April 2014

Subject Category: Cancer

Head and neck squamous cell carcinomas (HNSCCs) are the eighth and thirteenth most common malignancy in the world for males and females, respectively, affecting up to 600000 people each year. Among the various HNSCC subtypes, about $10 \%$ are oral squamous cell carcinoma (OSCC), which represents the most frequent of all oral neoplasms. It is estimated that more than $90 \%$ of all oral neoplasms are OSCC. ${ }^{1,2}$ Despite the advances in therapeutic approaches, percentages of morbidity and mortality of OSCC have still not significantly improved during the last 30 years with the 5-year overall survival rate for patients with OSCC varying between 40 and $50 \%$. Consumption of alcohol, tobacco, and betel nut as well as the infection by human papillomavirus $^{3-5}$ are considered risk factors that drive abnormal gene expression and contribute to the initiation and development of OSCC. ${ }^{6,7}$

Fibroblast Activation Protein, Alpha (FAP) is a homodimeric integral membrane gelatinase belonging to the serine protease family. In a previous study, FAP was found to be selectively expressed in reactive stromal fibroblasts of epithelial cancers, granulation tissue of healing wounds, and malignant cells of bone and soft tissue sarcomas. Exogenous FAP protein expression or FAP-overexpressing fibroblasts promoted cell proliferation and invasion in ovarian cancer and pancreatic cancer. ${ }^{8,9}$

Several investigations have indicated that FAP is expressed in epithelium-derived tumor cells including breast cancer, ${ }^{10}$ pancreatic cancer, ${ }^{11}$ gastric cancer, ${ }^{12}$ colorectal cancer, ${ }^{13}$ and cervical cancer ${ }^{14}$ and its elevated expression as an unfavorable factor promotes the poor progression for these cancers. However, the roles of endogenous FAP in such tumors were not reported. Thus, this study was designed to investigate the function and possible molecular basis of FAP in the pathogenesis of OSCC. Here, we demonstrated that FAP exerts an impact as a potential oncogene, which in turn contributes to the initiation and progression of OSCC.

\section{Results}

Increased expression of FAP is unfavorable for OSCC prognosis. Protein expression levels of FAP were measured in samples of 84 archived paraffin-embedded OSCC tissues and 12 non-cancerous oral cavity epithelium tissues using immunohistochemical staining (Figure 1-la-h). FAP protein immunostaining was mainly found on the cell membrane and in the cytoplasm of OSCC cells (Figure 1-II).

\footnotetext{
${ }^{1}$ Department of Stomatology of Nanfang Hospital, Southern Medical University, Guangzhou, PR China; ${ }^{2}$ Cancer Research Institute, School of Basic Medicine, Southern Medical University, Guangzhou, PR China and ${ }^{3}$ Department of Pathology, School of Basic Medicine, Guangzhou Medical University, Guangzhou, PR China

*Corresponding author: W Fang and X Lv, Oncology Cancer Research Institute, Southern Medical University, Tonghe Road, Guangzhou, Guangdong Province 510515, China. Tel: +86 02062789438; Fax: +86 02061648226; E-mail: Ivxia0zhi1975@163.com or fangweiyi1975@163.com

${ }^{4}$ These authors contributed equally to this work.

Keywords: FAP; OSCC; cell proliferation; metastasis; PTEN/AKT/PI3K; RAS/ERK

Abbreviations: FAP, fibroblast activation protein; OSCC, oral squamous cell carcinoma; PI3K, phosphoinositide 3-kinase; AKT, v-akt murine thymoma viral oncogene homolog 1; CAFs, cancer-associated fibroblasts; Ras, rat sarcoma viral oncogene homolog; MEK1, mitogen-activated protein kinase kinase 1; ERK, mitogen-activated protein kinase 1; GSK3 $\beta$, glycogen synthase kinase 3 beta; PTEN, phosphatase and tensin homolog; qRT-PCR, real-time quantitative reverse transcription PCR; MTT, 3-(4,5-Dimethylthiazol-2-yl)-2,5-diphenyltetrazoliumbromide; EMT, epithelial-mesenchymal transition

Received 1.11.13; revised 24.2.14; accepted 25.2.14; Edited by H-U Simon
} 
I

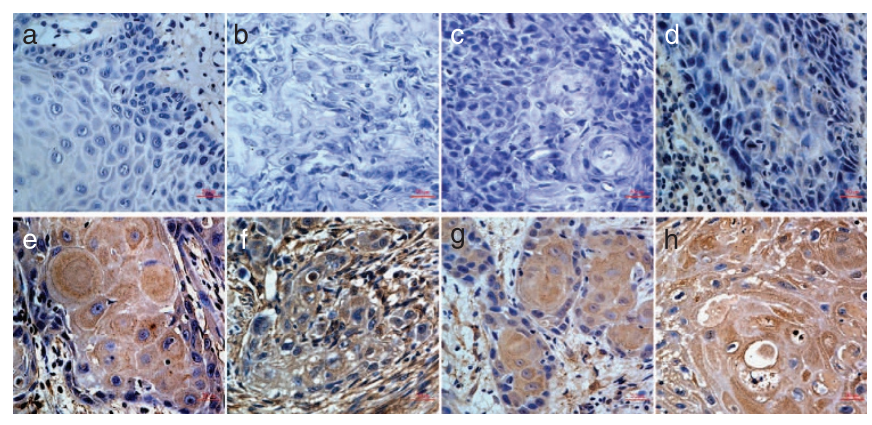

II

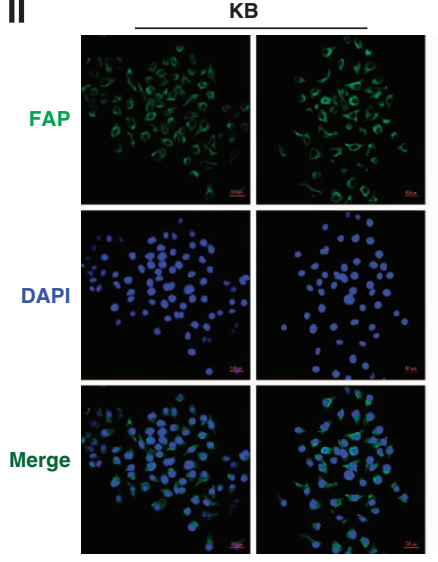

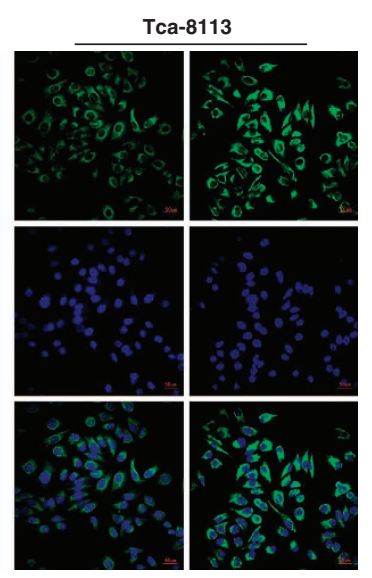

III

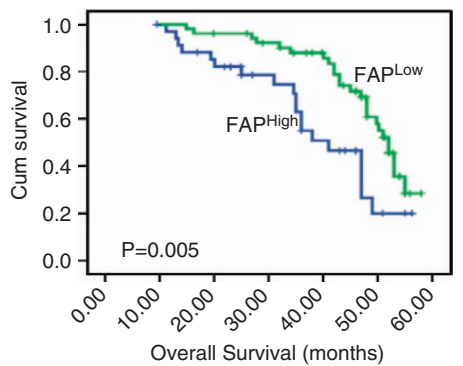

Figure 1 FAP expression in oral squamous cell carcinoma (OSCC) is associated with poor prognosis. (I) FAP expression examination in OSCC and control tissues (a) Negative FAP expression in oral cavity epithelium; $(b, c)$ Negative expression of FAP in OSCC tissues; $(d, e)$ Weakly positive expression of FAP in OSCC tissues; ( $f, g$, and $h$ ) Positive and strong positive expression of FAP in OSCC tissues; (II) Immunofluorescent images of KB and Tca-8113 cells stained for FAP (green) and 4',6-diamidino-2phenylindole (DAPI; blue) (magnification, $\times 400)$; (III) Kaplan-Meier survival analysis of overall survival in all patients. The log-rank test was used to calculate $P$-values

Furthermore, FAP expression in OSCC samples was relatively higher than in Benign samples $(P<0.0001)$ (Table 1). Further, we analyzed the relationship between clinicopathologic characteristics and FAP expression levels in individuals with OSCC (Table 2). Although we did not find a significant association of FAP expression levels with patient's age, sex, smoking status, alcohol, recurrence, tumor location, differentiation, and distant metastasis (M classification), we observed that the elevated expression level of FAP was markedly correlated with tumor size (T classification) (T1-T2 versus T3-T4) $(P=0.027)$, lymph-node metastasis $(\mathrm{N}$ classification) (N0-N1 versus N2-N3) $(P=0.015)$ and clinical stage (I-II versus III-IV) $(P=0.014)$ in OSCC patients. To investigate the prognostic value of FAP expression for OSCC, the follow-up data of 84 OSCC patients for up to 5 years were used to assess the value of FAP for predicting patient survival in OSCC patients. Kaplan-Meier survival analysis revealed a correlation between FAP expression level and overall survival times $(P=0.005)$ (Figure 1-III).

Stably downregulated or transiently silenced FAP expression suppresses cell proliferation in vitro and inhibits the growth of OSCC xenografts in vivo. To evaluate the functional significance of FAP on cell proliferation, we used a lentiviral shRNA vector to specifically and stably knock down the expression of FAP in KB cell line. The effect of shRNA transfection on the expression of FAP was confirmed by RT-PCR and western blot analysis.
Table 1 Immunohistochemistry analysis of FAP expression in OSCC

\begin{tabular}{lcccc}
\hline Group & $\boldsymbol{N}$ & \multicolumn{2}{c}{ FAP expression (\%) } & \multirow{2}{*}{$\boldsymbol{P}$-value } \\
\cline { 3 - 4 } & & Low & High & \\
\hline Non-cancerous tissues & 12 & $11(91.7 \%)$ & $1(8.3 \%)$ & $<0.0001$ \\
Carcinoma & 84 & $31(36.9 \%)$ & $53(63.1 \%)$ & \\
& & & &
\end{tabular}

The amount of FAP mRNA and protein, normalized by $\beta$-actin, was reduced up to $75 \%$ compared with the negative control cells (Figure 2a). Furthermore, we found that FAP knockdown in KB cells inhibited cell growth in vitro. The growth curves determined by MTT assay showed that suppressing FAP significantly reduced cell viability in comparison with sh-con cells (Figure $2 \mathrm{~b}$ ). Colony formation assay showed that suppressing FAP significantly reduced cell proliferation compared with sh-con cells (Figure 2c). Downregulated FAP expression in shRNA-FAP-1 and 2 cells inhibited cell-cycle transition from $\mathrm{G} 1$ to $S$ compared with sh-con cells (Figure 2d). To assess the effect of FAP on OSCC growth in vivo, we injected FAP-depleted KB cells, or their control cells into nude mice subcutaneously, and then monitored tumor growth. External fluorescent images can provide invaluable real-time data in tracking cancer growth. The tumor formation rate of KB/shRNA-FAP-1 and -2 cells was significantly lower than that of $\mathrm{KB} / \mathrm{shRNA}$-con cells (Figure 2e). 
Table 2 Correlation between expression of FAP protein and clinicopathological characteristics in OSCC patients $(n=84)$

\begin{tabular}{|c|c|c|c|c|}
\hline \multirow[t]{2}{*}{ Variables } & \multicolumn{4}{|c|}{ FAP (\%) } \\
\hline & $n$ & High expression & Low expression & $P$-value \\
\hline $\begin{array}{l}\text { Gender } \\
\text { Male } \\
\text { Female }\end{array}$ & $\begin{array}{l}54 \\
30\end{array}$ & $\begin{array}{l}24(44.4 \%) \\
11(36.7 \%)\end{array}$ & $\begin{array}{l}30(55.6 \%) \\
19(63.3 \%)\end{array}$ & 0.645 \\
\hline $\begin{array}{l}\text { Age (years) } \\
\geq 54 \\
<54\end{array}$ & $\begin{array}{l}35 \\
49\end{array}$ & $\begin{array}{l}15(42.9 \%) \\
17(47.2 \%)\end{array}$ & $\begin{array}{l}20(57.1 \%) \\
32(52.8 \%)\end{array}$ & 0.813 \\
\hline $\begin{array}{l}\text { Smoking } \\
\text { Yes } \\
\text { No }\end{array}$ & $\begin{array}{l}38 \\
46\end{array}$ & $\begin{array}{l}18(47.4 \%) \\
16(33.3 \%)\end{array}$ & $\begin{array}{l}20(52.6 \%) \\
30(66.7 \%)\end{array}$ & 0.267 \\
\hline $\begin{array}{l}\text { Site } \\
\text { Tongue } \\
\text { Buccal mucosa } \\
\text { Gingival } \\
\text { Other }\end{array}$ & $\begin{array}{l}38 \\
24 \\
18 \\
4\end{array}$ & $\begin{array}{l}25(65.8 \%) \\
16(66.7 \%) \\
11(61.1 \%) \\
3(75 \%)\end{array}$ & $\begin{aligned} & 13(34.2 \%) \\
& 8(33.3 \%) \\
& 7(38.9 \%) \\
& 1(25 \%)\end{aligned}$ & 0.955 \\
\hline $\begin{array}{l}\text { Differentiation } \\
\text { Well differentiated } \\
\text { Moderate to poorly differentiated }\end{array}$ & $\begin{array}{l}32 \\
52\end{array}$ & $\begin{array}{l}20(62.5 \%) \\
38(70.4 \%)\end{array}$ & $\begin{array}{l}12(37.5 \%) \\
16(29.6 \%)\end{array}$ & 0.483 \\
\hline $\begin{array}{l}\text { Alcohol } \\
\text { Yes } \\
\text { No }\end{array}$ & $\begin{array}{l}29 \\
55\end{array}$ & $\begin{array}{l}17(58.6 \%) \\
39(70.9 \%)\end{array}$ & $\begin{array}{l}12(41.4 \%) \\
16(29.1 \%)\end{array}$ & 0.331 \\
\hline $\begin{array}{l}\text { Recurrence } \\
\text { Yes } \\
\text { No }\end{array}$ & $\begin{array}{l}19 \\
65\end{array}$ & $\begin{array}{l}12(63.2 \%) \\
38(58.5 \%)\end{array}$ & $\begin{array}{r}7(36.8 \%) \\
27(41.5 \%)\end{array}$ & 0.795 \\
\hline $\begin{array}{l}T \text { classification } \\
\text { T1 }+ \text { T2 } \\
\text { T3 }+ \text { T4 }\end{array}$ & $\begin{array}{l}48 \\
26\end{array}$ & $\begin{array}{l}21(43.8 \%) \\
19(73.1 \%)\end{array}$ & $\begin{array}{r}27(56.2 \%) \\
7(26.9 \%)\end{array}$ & 0.027 \\
\hline $\begin{array}{l}N \text { classification } \\
\text { N0 }+ \text { N1 } \\
\text { N2 }+ \text { N3 }\end{array}$ & $\begin{array}{l}51 \\
33\end{array}$ & $\begin{array}{l}23(45.1 \%) \\
24(72.7 \%)\end{array}$ & $\begin{array}{r}28(54.9 \%) \\
9(27.3 \%)\end{array}$ & 0.015 \\
\hline $\begin{array}{l}\text { Distant metastasis } \\
\text { M1 } \\
\text { M0 }\end{array}$ & $\begin{array}{c}6 \\
78\end{array}$ & $\begin{array}{r}5(83.3 \%) \\
38(55.9 \%)\end{array}$ & $\begin{array}{r}1(16.7 \%) \\
30(44.1 \%)\end{array}$ & 0.391 \\
\hline $\begin{array}{l}\text { Clinical stage } \\
\text { I-II } \\
\text { III-IV }\end{array}$ & $\begin{array}{l}50 \\
34\end{array}$ & $\begin{array}{l}18(36.0 \%) \\
22(64.7 \%)\end{array}$ & $\begin{array}{l}32(64.0 \%) \\
12(35.3 \%)\end{array}$ & 0.014 \\
\hline
\end{tabular}

Bold values indicate statistical significance, $P<0.05$

Interestingly, similar results were also observed in small-interfering RNA (siRNA)-mediated suppression of FAP in OSCC cells. We found that knocking down endogenous FAP expression not only reduced the expression of FAP (Figure $3 a$ ), but also decreased cell proliferation (Figure $3 b$ ) and the G1/S transition in OSCC KB and Tca-8113 cells (Figure $3 \mathrm{c}$ ), compared with their respective Si-Con-treated OSCC cells. Taken together, these results suggested that FAP significantly promoted cell growth in vitro and vivo.

Knockdown of FAP attenuates cell migration and invasion in vitro and in vivo. To investigate the effects of FAP on cancer cell migration and invasive ability, we examined the cellular invasion, migration following silencing of FAP in KB and Tca-8113 cells. In a wound-healing assay, silencing of FAP markedly slowed cell migration at the edges of scratch wound of KB cells (Figure 4a). Quantitative analyses at $48 \mathrm{~h}$ confirmed a significant reduction in wound closure in FAP-silenced cells compared with empty vectortransfected control cells (Figure 4a). In addition, Matrigel invasion assay showed that KB cells with downregulated FAP were much less invasive than controls (Figure 4b). Next, we analyzed the adhesion ability of the FAP shRNA-treated $\mathrm{KB}$ cells using a solid-phase assay combined with the MTT assay. For the same surface-coated concentration of $\mathrm{FN}$, adhesion of the FAP shRNA-treated cells was significantly higher than the control cells (Figure 4c). Alterations in the cellular cytoskeleton organization and polarity are also involved in tumor cell metastasis. ${ }^{15}$ Therefore, we examined the cytoskeleton structures of the FAP shRNA-treated cells by the phalloidin staining and found that the 'feet' of the FAP shRNA-treated cells was shortened and that the cellular polarity was weakened compared with the control cells (Figure 4d). To assess the effect of FAP on OSCC metastasis in vivo, FAP-depleted KB cells and their control cells were independently injected into the spleens of nude 

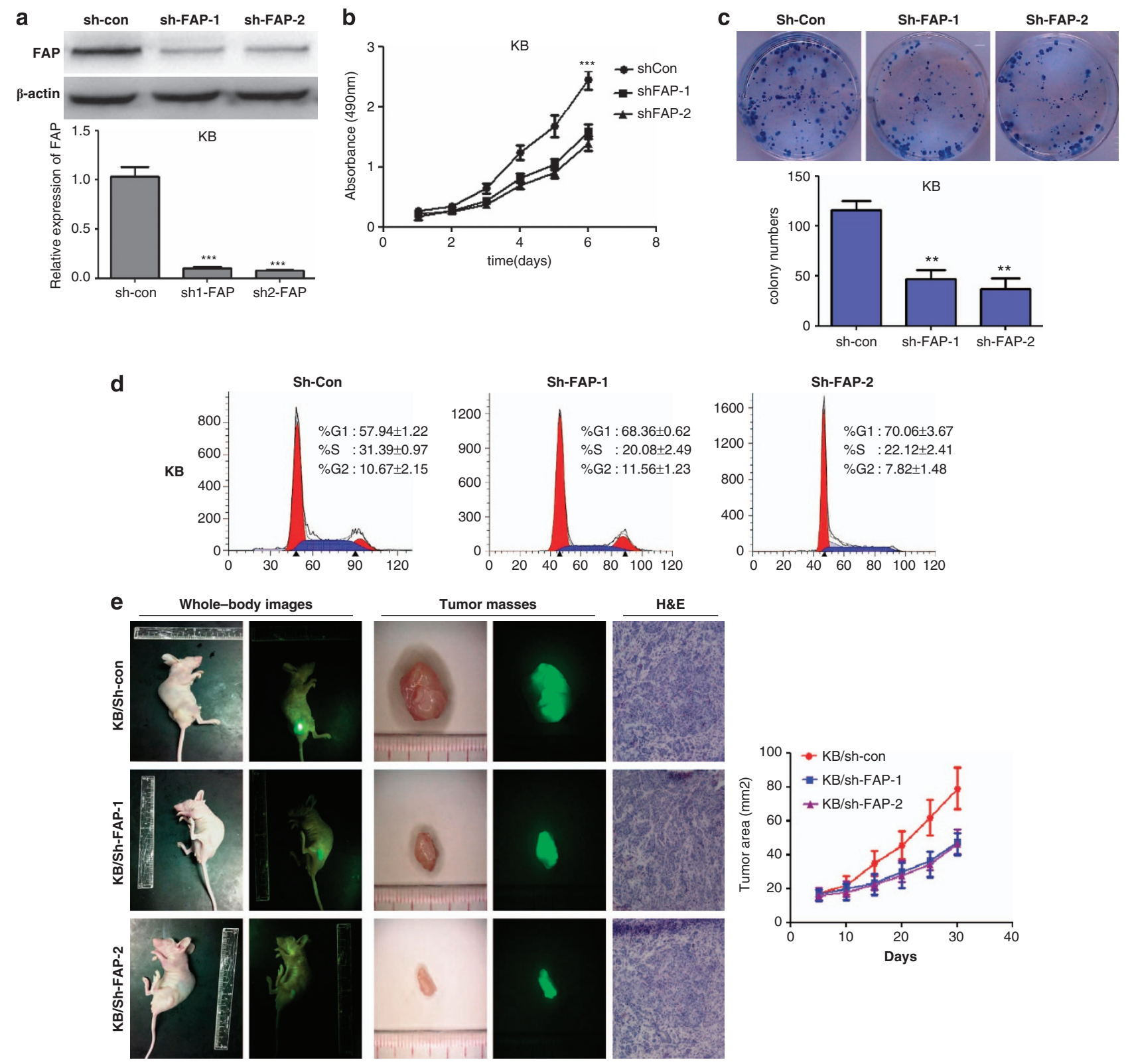

Figure 2 Stable suppression of FAP attenuates the growth of OSCC cells in vitro and vivo. (a) Stably knocking down decreased the expression of FAP in shRNA-FAP-1 and -2 cells compared with shRNA-con cells by real-time PCR and western blotting. $\beta$-Actin was used as a loading control. (b) MTT cell viability assays were performed on days 1-6 of KB cells stably expressing the shRNA-FAP-1 and 2 or shRNA-con vectors. (c) Colony formation assay was performed on KB cells stably expressing the shRNAFAP-1 and -2 or shRNA-con vectors for 2 weeks. (d) Cell-cycle analysis of KB cells stably expressing the shRNA-FAP-1 and 2 or shRNA-con vectors. (e) External whole-body fluorescence images of KB/shRNA-FAP-1 and -2 and KB/shRNA-con mice obtained 30 days after injection. Representative photographs of $H \& E$ staining of primary cancer tissues are shown. Data are presented as mean \pm S.D. for three independent experiments ${ }^{* *} P<0.01 ;{ }^{* * *} P<0.001$, compared with control

mice. Fluorescence images showed a few scattered metastatic nodules in livers of nude mice were formed in the mice injected with $\mathrm{KB} / \mathrm{shRNA}-\mathrm{FAP}-1$ and 2 cells, while a variety of large clusters were observed in KB/shRNA-con cells. This is consistent with the H\&E-stained liver sections showing extensively distributed large metastatic nodules in mice injected with $\mathrm{KB} / \mathrm{shRNA}$-con cells, while only a few scattered metastatic cells were observed on the section of the mice injected with KB/shRNA-FAP-1 and -2 cells (Figure 4e). Similar to the stably suppressed FAP expression results, suppressing FAP expression using siRNA-FAP also reduced cell migration, invasion, and adhesion ability in $\mathrm{KB}$ and Tca-8113 cells (Figures $5 a-c$ ).

FAP modulates the expression of multiple genes involved in the cell cycle, MMPs, and EMT in OSCC. To obtain further insight into the mechanisms of FAP in OSCC cell proliferation, migration, and invasion, we examined protein levels of cell cycle, MMP, and EMT-associated genes in OSCC KB cells with stably suppressed FAP expression. Silencing endogenous FAP expression reduced the activation of $\mathrm{pRb}(\mathrm{Ser} 780)$ and oncogenic cell-cycle regulators 


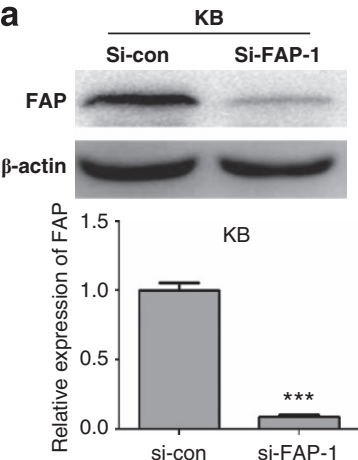

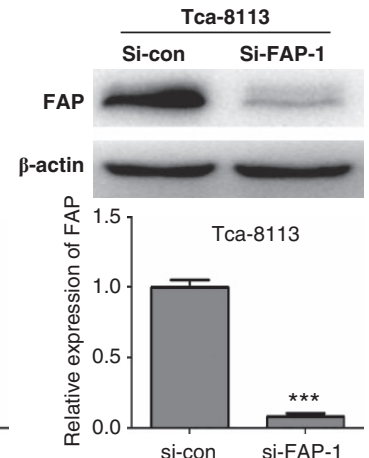

b
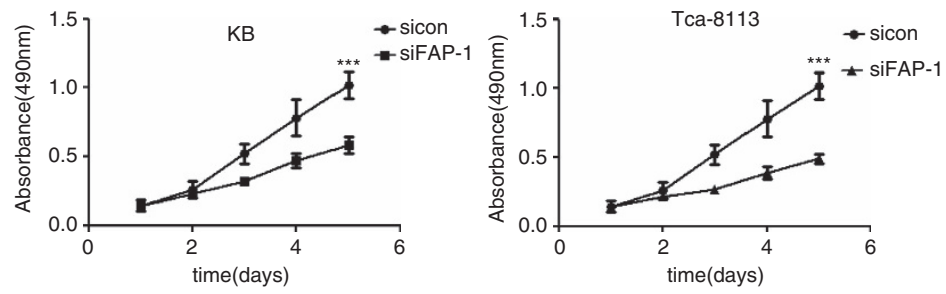

c

KB
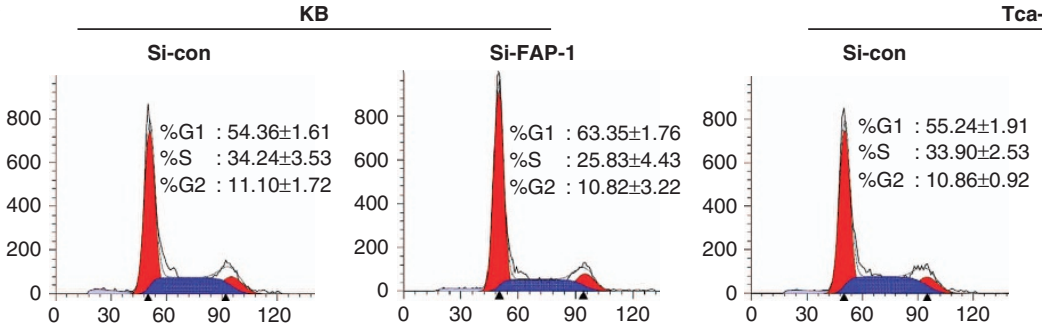

ca-8113

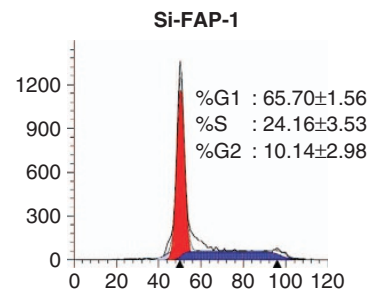

Figure 3 Transient suppression of FAP inhibits growth of OSCC cells in vitro. (a) Transiently knocking down FAP by siRNA reduced the expression of FAP by real-time PCR and western blotting. (b) MTT cell viability assays was performed on days 1-5 after the transfection of KB and Tca-8113 cells with either siRNA FAP-1 or the negative control. (c) Cell-cycle profiles were analyzed after KB and Tca- 8113 cells were transfected with siRNA FAP-1 or the negative control for $48 \mathrm{~h}$. Data are presented as mean \pm S.D for three independent experiments ${ }^{\star} P<0.05 ;{ }^{* \star} P<0.01 ;{ }^{* \star} P<0.001$, compared with control

including CCNE1, E2F1, and c-Myc, but elevated the expression of tumor suppressors such as p27 and p21. The expression of CDK4, CCND1, and total Rb was not affected (Figure 6a). Morphologic and phenotypic EMT-like changes are accompanied by the downregulation of epithelial marker E-cadherin and upregulation of mesenchymal markers, such as Vimentin, N-cadherin, MMP-2, and MMP-9. ${ }^{16,17}$ We examined the expression of epithelial and mesenchymal markers in FAP-silenced KB cells and found decreased expression of MMP2, MMP9, and EMT-marker genes including Snail, Slug, N-cadherin, and Vimentin while $\mathrm{E}$-cadherin expression increased (Figure 6b).

FAP regulates proliferation, migration, and invasion through PTEN/PI3K/Akt and Ras-ERK signaling pathways in OSCC cells. Mounting evidence indicates that cell cycle, EMT, and MMPs signaling are regulated by GSK3 $\beta$, a downstream target of the PI3K/Akt and Ras-ERK signaling pathways. ${ }^{18,19}$ We examined the effect of FAP on PTEN/ PI3K/Akt and Ras-ERK signaling pathways and found that reduced FAP significantly decreased the expression of phosphorylated PI3K, AKT, MEK1/2, ERK1/2, and GSK3 $\beta$, whereas total levels remained unchanged (Figure $6 c$ ). Meanwhile we also found that PTEN, an upstream target of the PI3K/Akt signaling pathway, was upregulated in FAP-suppressed cells. These results suggested that FAP is an upstream factor modulating the PTEN/PI3K/Akt and Ras-ERK signaling pathways in OSCC.

PTEN depletion or introduction of PTEN respectively enhances or decreases proliferation, migration, and invasion of OSCC cells in vitro. To better understand the role of PTEN/PI3K/Akt and Ras-ERK signaling pathways in FAP-regulated growth and metastasis of OSCC cells, siRNA transfection was employed to knockdown PTEN expression in KB/shRNA-FAP-1 cells, which had silenced endogenous FAP expression. Knockdown efficiency was evaluated by both real-time $\mathrm{qRT}-\mathrm{PCR}$ and western blotting (Figure 7a). MTT assay showed that PTEN knockdown increased the cell growth rate (Figure $7 \mathrm{~b}$ ). Matrigel invasion assay demonstrated that depletion of PTEN in KB/shRNAFAP-1 cells strongly elevated cell invasion (Figure 7c). Wound-healing assay suggested the rate of wound healing was markedly higher in PTEN-downregulated KB/shRNAFAP-1 cells than in controls (Figure 7d). These results suggested that knockdown of PTEN expression in KB/shRNA-FAP-1 cells could dramatically enhance proliferation, migration, and invasion. Inversely, introduction of wild-type PTEN ( $p E G F P$-wt-PTEN) markedly reduced cell proliferation and invasion compared with mutant-type PTEN (pEGFP-G129R-PTEN) and empty vector (pEGFP-C1) in $\mathrm{KB} / \mathrm{shRNA}-\mathrm{FAP}-1$ cells growth rate (Figure $7 \mathrm{e}$ ) and cell invasion (Figure 7f).

\section{Discussion}

In previous studies, FAP- $\alpha$ was found to be selectively and highly expressed on the surface of cancer-associated fibroblasts surrounding examined epithelial cancers including breast, colorectal, pancreatic, and lung cancers. ${ }^{20-23}$ However, FAP was recently observed to be expressed in epithelium-derived tumor cells, ${ }^{10-14}$ which suggested that FAP expression in epithelium was associated with the pathogenesis. Interestingly, the role and molecular basis of FAP linking the initiation and development of these tumors have not been reported. 
a

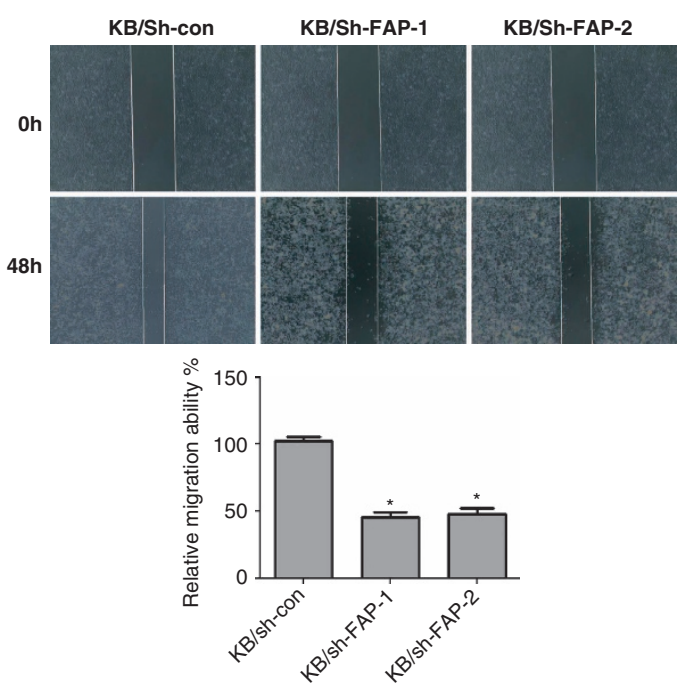

b
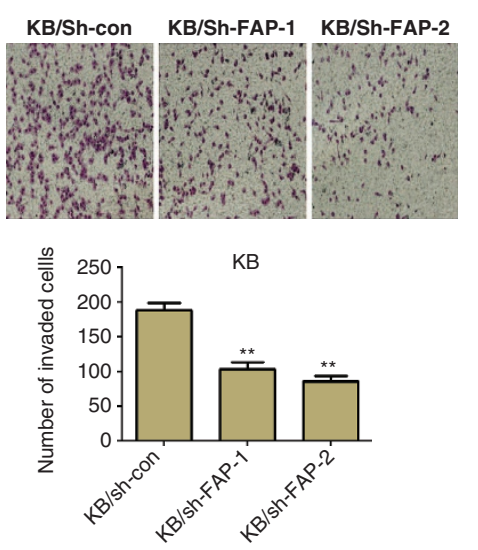

C
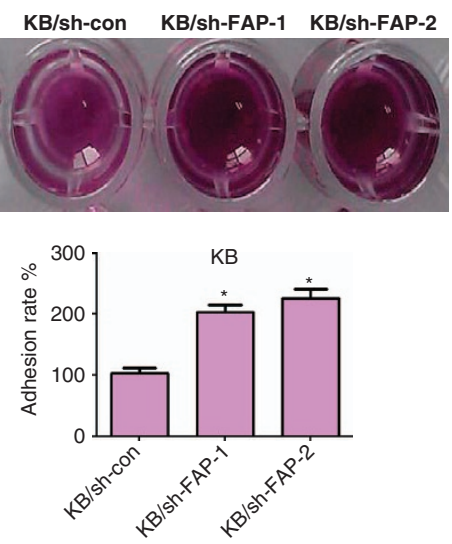

d

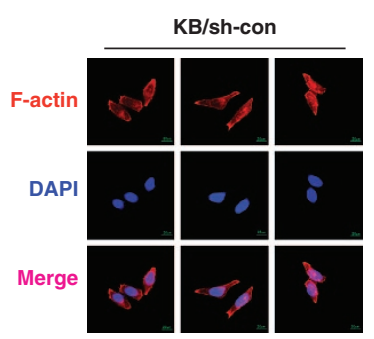

KB/sh-FAP-1

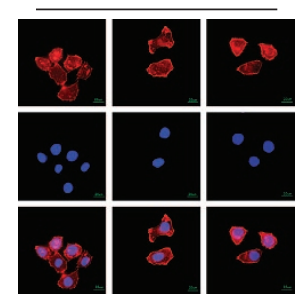

e

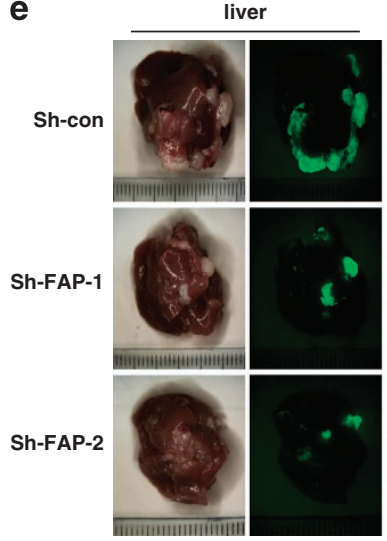

H\&E

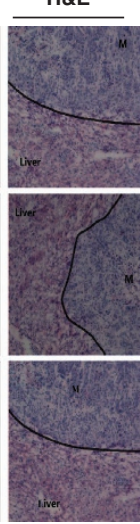

Figure 4 Stable depletion of FAP suppresses cell migration and invasion in vitro and vivo. (a) Wound-healing assay showed KB cells stably expressing the shRNA-FAP-1 and -2 or shRNA-con vectors at 0 and $48 \mathrm{~h}$ after wounding. Bar chart showing the relative migration ability at $48 \mathrm{~h}$. (b) Cell invasion assay showed decreased invasion from cells transfected with shRNA-FAP-1 and -2, with representative fields shown. (c) The ability of the cells to adhere to a solid surface was significantly increased in cells treated with shRNA-FAP-1 and -2, and a representative experiment is shown. Bar chart showing the adhesive rate quantified by MTT assay. (d). Phalloidin staining of F-actin in KB/ shRNA-FAP-1 and KB/shRNA-con cells (magnification, $\times 1000$ ). (e) External whole-body fluorescence images of liver were obtained 2 months after spleen injection, respectively. Metastatic cancer tissue (H\&E staining, magnification, $\times 200$ ). Data shown are means \pm S.D. of at least three independent experiments ${ }^{*} P<0.05 ;{ }^{* \star} P<0.01$, compared with control

In this study, FAP was confirmed to be expressed in OSCC cells by western blotting and immunofluorescence, which represented an ideal model to study the role and molecular mechanisms of FAP. We found that stably decreased expression of FAP converted KB cells into less aggressive cells, with lower capability of cell-cycle G1/S transition, cell growth in vitro and in vivo, cell adhesion, migration, and invasion in vitro as wells as metastasis in vivo. Interestingly, similar results were also observed in siRNA-FAP-treated KB and Tca-8113 OSCC cells. Furthermore, we also found that shRNA-FAP-treated cells were shortened and the cellular polarity was weakened compared with control cells. These results together suggest that endogenous FAP expression acts as an oncogene in OSCC cells.

The biological functions of FAP found in this study provide a mechanistic basis in OSCC. It is well known that high proliferative activity of tumor cells is associated with the increased cell-cycle transition. ${ }^{24}$ In this study, we observed that suppressing FAP expression blocked cell growth by inhibiting cell-cycle progression and modulating cell cyclerelated factors including downregulating c-Myc, CCNE1, pRB, and E2F1 as well as upregulating p21 and p27 expression. There is accumulating evidence that the EMT confers adhesion, migration, invasion, and metastasis capacity, stemness and multidrug resistance in tumor cells. ${ }^{25-29}$ Thus, EMT may have a critical role in tumor progression. In the present study, we showed that suppressed expression of FAP decreased OSCC cell adhesion, migration, invasion, and metastasis capacity and induced EMT by elevating expression of the epithelial marker E-cadherin and reducing expression of the mesenchymal markers $\mathrm{N}$-cadherin and vimentin. Furthermore, transcription factors Slug and Snail were altered providing the first evidence that FAP is itself sufficient to induce the EMT. Finally, our findings also indicated that knocking down FAP expression attenuated the expression of MMP2 and MMP9, two key members of 
a
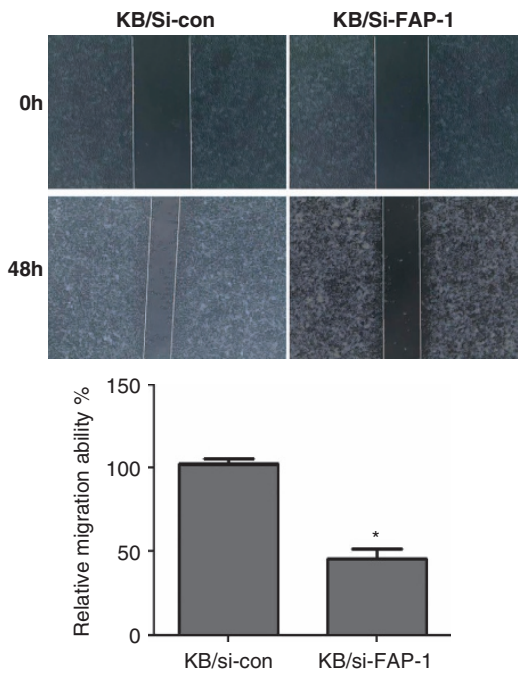

b
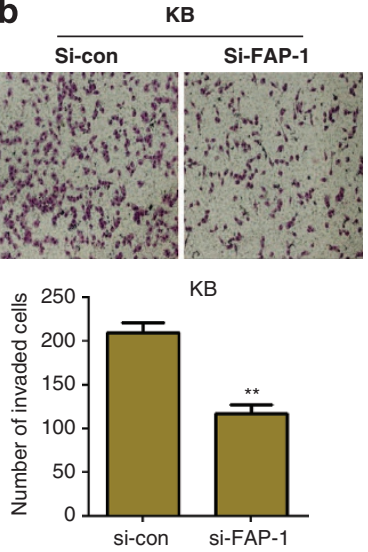
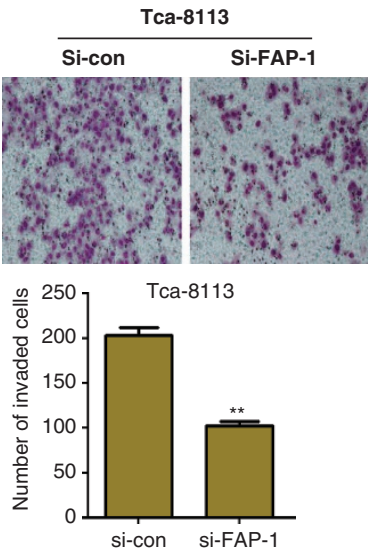
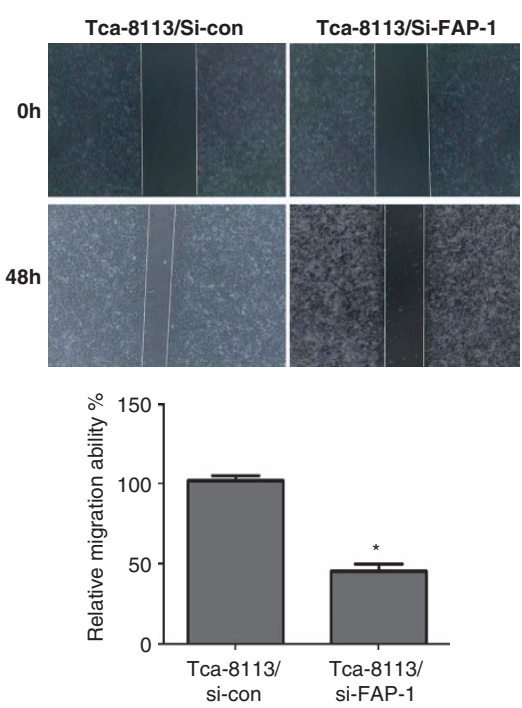
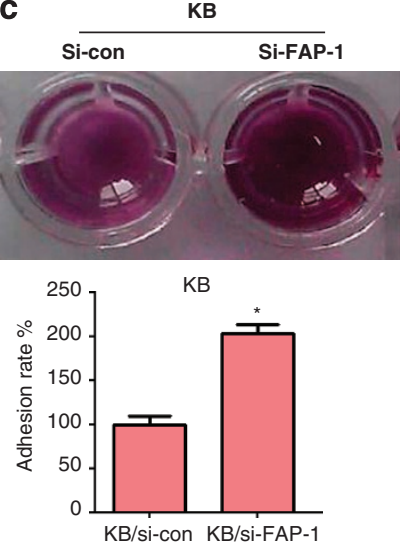
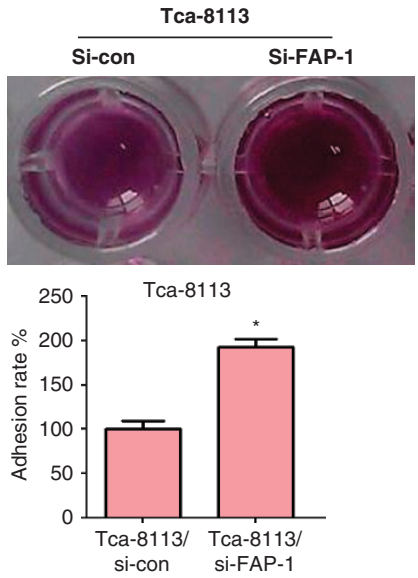

Figure 5 Transient depletion of FAP reduces cell migration and invasion in vitro. (a) Transiently downregulated FAP dramatically inhibited KB and Tca-8113 cell migration in vitro. (b) Transiently suppressed FAP decreased in vitro invasiveness of KB and Tca-8113 cells. (c) Transient knockdown of FAP elevated the adhesion rate of KB and Tca-8113 cells. Data are presented as means \pm S.D. of at least three independent experiments ${ }^{*} P<0.05 ;{ }^{*} P<0.01$, compared with control

matrix metalloproteinase (MMP) family that facilitate cell invasion and metastasis in many tumors. ${ }^{30-32}$

In previous reports, activated PI3K/AKT was documented as a classical signaling pathway inducing pGSK-3 $\beta$ expression, which stimulates c-Myc-mediated signaling of cell-cycle progression. This promotes cell proliferation, ${ }^{33}$ increases the expression of Snail and Slug inducing EMT transition, ${ }^{34,35}$ and elevates secretion of MMP2 and MMP9 facilitating cell invasion. ${ }^{36}$ Our results suggest that inactivated PI3K/AKT signaling is responsible for shRNA-FAP-mediated suppression of tumor cell proliferation, adhesion, invasion, and EMT. In addition, it has a role in hypophosphorylation of GSK3b, attenuated expression of c-Myc, pRB, CCNE1, E2F1, Snail, Slug, Vimentin, N-cadherin, MMP2, MMP9, and elevated expression of p21, p27, and E-cadherin in OSCC cells. Further, PTEN, ${ }^{37}$ a well-known tumor suppressor that inhibits the activation of $\mathrm{PI} / 3 \mathrm{~K} / \mathrm{AKT},{ }^{38}$ was found to be upregulated in shRNA-FAP cells compared with control cells. Knocking down PTEN expression or introduction of PTEN gene could respectively increase or reduce the aggressive phenotypes in OSCC cells with stable suppression of FAP. These findings suggest that FAP-mediated inhibition of PTEN activates PI3K/ AKT/GSK-3 $\beta$ signaling, which in turn induces cell proliferation, migration, invasion, and metastasis in OSCC.

ERK signaling is also a classical pathway that stimulates GSK-3 $\beta$ phosphorylation and further induces c-Myc-mediated cell-cycle signaling to promote cell proliferation. This also stimulates Snail-modulated EMT critical for cell migration, invasion, and metastasis. In this study, we also observed the inactivation of pMEK and pERK after knocking down FAP in OSCC cells compared with control cells. This result is similar to Yang et al.'s report ${ }^{8}$ and suggested that ERK signaling positively mediates FAP-stimulated cell growth and the EMT program.

FAP expression has been described to be present predominantly in cancer-associated fibroblasts of many human epithelial malignancies. Elevated expression of FAP was also associated with histological grade, invasion, and metastatic progression. In this study, we also examined the expression of FAP in OSCC tissues and evaluated the correlation of FAP expression with clinical features. Our findings suggest that FAP is expressed in OSCC cells and its 

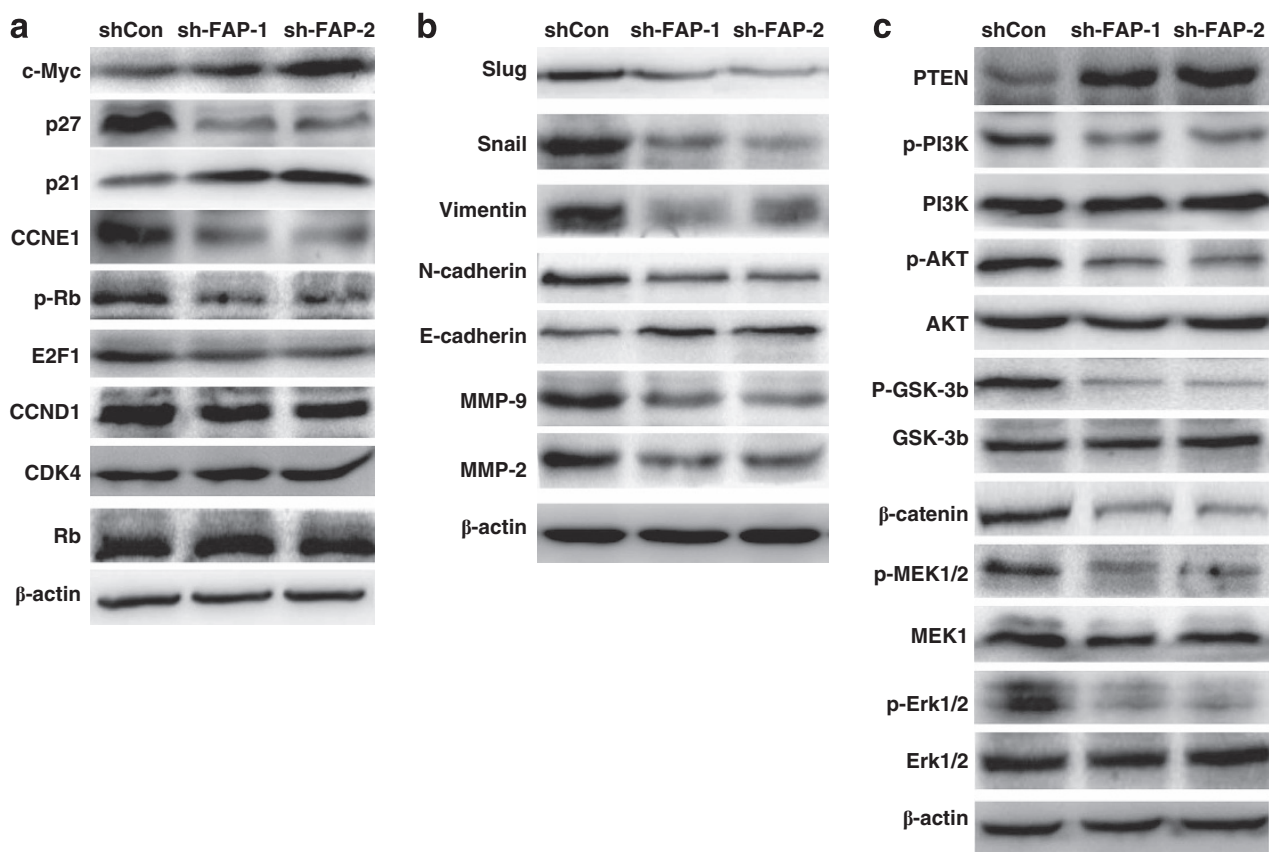

Figure 6 FAP regulates the expression of cell cycle, MMPs, and EMT-associated genes in OSCC through PTEN/PI3K/Akt and ERK signaling pathways. (a) Knocking down endogenous FAP expression reduced the activation of $\mathrm{pRb}($ ser780), an oncogenic cell-cycle regulator including CCNE1, E2F1, and c-Myc, and elevated the expression of tumor suppressors including p27 and p21. However, the expression of CDK4, CCND1, and total Rb was not affected. (b) Suppressing FAP expression decreased the expression of MMP2, MMP9, and EMT-marker genes including Snail, Slug, N-cadherin, and Vimentin but increased E-cadherin expression. (c) Reduced FAP significantly decreased the expression of phosphorylated PI3K, AKT, MEK1/2, ERK1/2, and GSK3 $\beta$, whereas total levels remained unchanged. $\beta$-Actin was used as a loading control

overexpression is positively correlated with clinical progression of OSCC patients. We further analyzed the correlation of FAP expression in OSCC cells with patient survival. As expected, increased expression of FAP was associated with shorter overall survival in patients with OSCC. Together, FAP served as an independent prognostic indicator for OSCC.

In summary, we provided evidence that knocking down endogenous FAP suppresses cell proliferation, adhesion, migration, invasion, and metastasis by inactivating PTEN/ PIJK/AKT and Ras-ERK signaling. This in turn inhibits GSK$3 \beta$ and its downstream signals including cell-cycle regulators, EMT, and MMPs in OSCC. Furthermore, we observed that increased FAP expression facilitates the progression and poor prognosis of OSCC. Our studies demonstrated that FAP is a potential oncogene participating in OSCC pathogenesis.

\section{Materials and Methods \\ Cell culture, tissue collection, and Ethics Statement. OSCC cell lines KB and Tca-8113 were maintained in RPMI-1640 supplemented with 10\% newborn calf serum (NBCS) (PAA Laboratories, Inc., Pasching, Austria). In all, 84 paraffin-embedded OSCC specimens and 12 paraffin-embedded non-cancerous control tissues were obtained at the time of diagnosis before any therapy from Nanfang Hospital of Southern Medical University, Guangzhou. In 84 cases, there were 54 males and 30 females with ages ranging from 31 to 83 years (mean age: 54.13 years). For the use of these clinical materials for research purposes, prior written informed consents from all the patients and approval from the Ethics Committees of Nanfang Hospital of Guangdong Province were obtained. All specimens had confirmed pathological diagnosis and were staged according to the 2009 UICC-TNM Classification of Malignant Tumors.}

Establishment of lentivirus-delivered shFAP in OSCC cells. The preparation of lentivirus expressing human FAP short hairpin RNA (shRNA1247,1386) (Supplementary Table 1) was performed using the pLVTHM-GFP lentiviral RNAi expression system, which has been described in previous studies. ${ }^{39,40}$ The lentiviral particles were used to infect OSCC cell lines KB, and the levels of OSCC protein expression were measured using western blot assays.

Plasmid construction and transfection. Eukaryotic expression vectors of the wild type (pEGFP-wt-PTEN) and the mutant type (pEGFP-G129R-PTEN) of PTEN were constructed by Guangzhou Sagene (Sagene Incorporation, Guangzhou, China). KB/shRNA-FAP-1 cells were transfected with empty vector (pEGFP-C1), the wild-type vector (pEGFP-wt-PTEN) and the mutant-type vector (pEGFP- G129R-PTEN) by Lipofectamine 2000. Culture medium containing G418 was used to select stable transfectants.

Transient transfection with siRNAs for FAP. siRNA for FAP and PTEN was designed and synthesized by Guangzhou RiboBio (RiboBio Inc., Guangzhou, PR China). The sequence of each gene and their controls are shown in Supplementary Table 2. Twenty-four hours before transfection, OSCC KB cells were plated onto a 96-well plate or a 6-well plate (Nest Biotechnology Co, Ltd., Shanghai, PR China) at a $30-50 \%$ confluence. They were then transfected into cells using TurboFect siRNA Transfection Reagent (Fermentas, Vilnius, Lithuania) according to the manufacturer's protocol. Cells were collected after $48-72 \mathrm{~h}$ for the further experiments.

RNA isolation, reverse transcription, and qRT-PCR. Total RNA was extracted from the shFAP and its mock cells using Trizol (Takara, Shiga, Japan). For FAP, RNA was transcribed into CDNA and amplified with specific sense: 5-TGTGCATTGTCTTACGCCCT-3; antisense primer: 5-CCGATCAGGTGATA AGCCGT-3. For PTEN gene, the forward (5-TGGATTCGACTTAGACTTGACCT-3) and reverse (5-TTGGCGGTGTCATAATGTCTT-3). Reverse transcription and QPCR were performed in accordance with manufacturer's instructions (Takara). The PCR for each gene was repeated three times. GAPDH was used as an internal control to normalize FAP expression. Differential expression of FAP was calculated using the $2^{-\Delta \Delta \mathrm{Ct}}$ method.

Western blotting. Western blotting was performed using a SDS-PAGE Electrophoresis System according to the previous ${ }^{39,40}$ description with rabbit polyclonal anti-FAP antibody (1: 1000; LifeSpan BioSciences Inc., Seattle, WA, USA), anti- $\beta$-actin, CCND1, CDK4, p21, E2F1, and p27 (1:500; Santa Cruz Biotechnology, Santa Cruz, CA, USA), anti-C-Myc, PTEN, $\beta$-catenin, GSK-3b, 

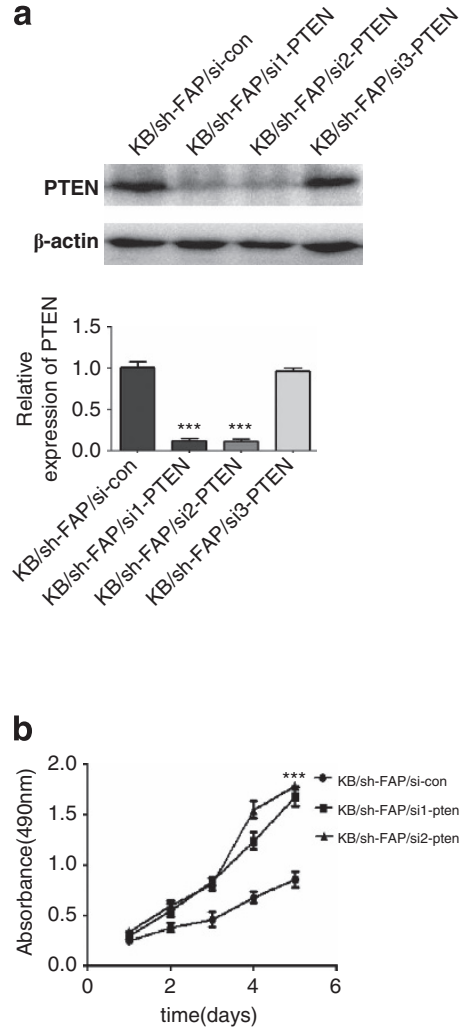
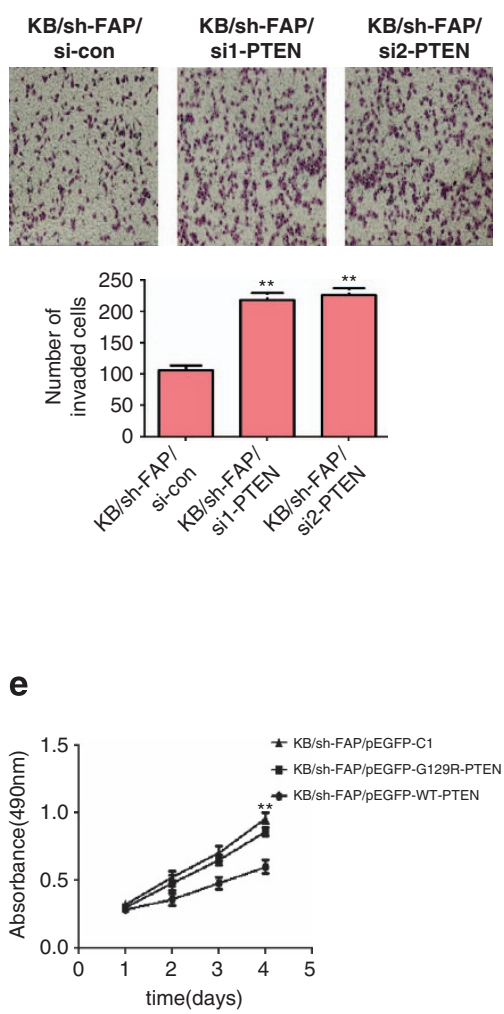

d

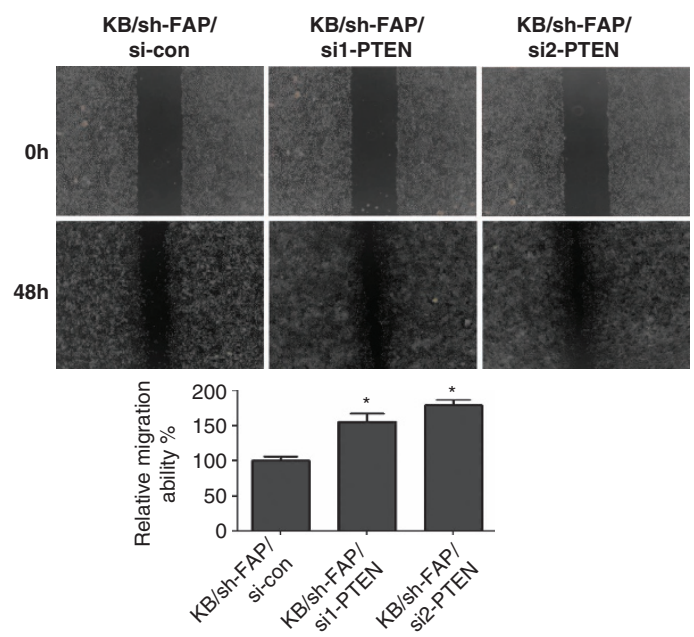

f

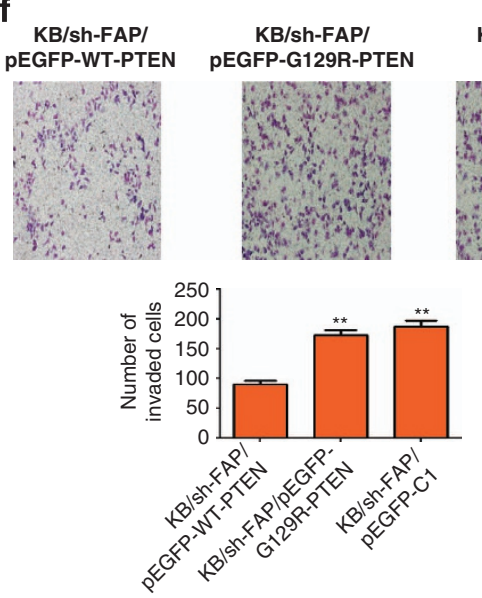

KB/sh-FAP/ pEGFP-C1

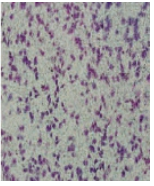

Figure 7 PTEN depletion or gain respectively elevates or decreases proliferation, migration, and invasion of cells with downregulated FAP. (a) Decreased PTEN mRNA and protein levels in KB cells with stably silenced FAP and transfected with siRNA were found by real-time PCR and western blotting. (b) MTT cell viability assays were performed on days 1-5 after the transfection of FAP knockdown KB cells with either siRNA PTEN-1 and -2 or the control. (c) Transiently downregulated PTEN dramatically enhanced the ability of KB cells treated with shRNA-FAP-1 invasion in vitro. (d) Transiently suppressed PTEN elevated in vitro migration of KB cells that had stable downregulated FAP. (e) MTT cell viability assays were performed on days 1-4 after the transfection of FAP knockdown KB cells with either the wild type (pEGFP-wt-PTEN) and the mutant type (pEGFP-G129R-PTEN) or empty vector (pEGFP-C1). (f) Introduction of PTEN decreased invasion of KB cells treated with shRNA-FAP-1. Data are presented as mean \pm S.D. for three independent experiments ${ }^{\star} P<0.05$; ${ }^{\star \star} P<0.01 ;{ }^{* \star} P<0.001$, compared with control

p-GSK-3b(ser-9), p-Erk1/2(Tyr202/Tyr204),Erk1/2, p-MEK1/2 (Ser-217/221), MEK1,CCNE1, MMP2, MMP9, p-RB (ser780), RB, AKT, p-Akt (Ser-473), PI3K, p-PI3K (Tyr458), p16, p27, Slug, Snail, Vimentin, N-cadherin, and E-cadherin (1:1000; Cell Signaling Technology, Danvers, MA, USA). Signals were detected using enhanced chemiluminescence reagents (Pierce, Rockford, IL, USA).

Immunofluorescence. OSCC cells were seeded on coverslips in 6-well plate and cultured overnight. Subsequently cells were fixed in 3.5\% paraformaldehyde, permeabilized in $\mathrm{KB}$ solution and $0.2 \%$ Triton $\mathrm{X}-100$ at room temperature. After the blocking solution was washed out, cells were incubated with a primary antibody (FAP) (diluted in $\mathrm{KB}$ ) $30-45$ min at $37^{\circ} \mathrm{C}$ and subsequently washing with $\mathrm{KB}$ twice. After incubating $30-45$ min at $37^{\circ} \mathrm{C}$ with secondary antibody (diluted in $\mathrm{KB}$ ), washing with $\mathrm{KB}$ again, the coverslips were then mounted onto slides with mounting solution containing $0.2 \mu \mathrm{g} / \mathrm{ml} \mathrm{DAPI}$ and sealed with nail polish. The F-actin status was analyzed by phalloidin staining (Abbkine, Inc., Redlands, CA, USA) for $45 \mathrm{~min}$ at room temperature. Slides were stored at $4^{\circ} \mathrm{C}$ in a dark box and observed under a fluorescent microscope.

MTT assay. 3-(4, 5-dimethylthiazol-2-yl)-2, 5-diphenyltetrazolium bromide (MTT) assay was used to evaluate the rate of in vitro cell proliferation. For
ShFAP cells and siFAP cells, they were seeded in 96-well plates at a density of 1000 cells/well and respectively incubated for $1,2,3,4,5,6$, or 7 days or $1,2,3$, 4 , or 5 days. Twenty microliters of MTT ( $5 \mathrm{mg} / \mathrm{ml}$ ) (Sigma, St. Louis, MO, USA) was added to each well and incubated for $4 \mathrm{~h}$. At the end of incubation, the supernatants were removed, and $150 \mu$ of DMSO (Sigma) was added to each well. The absorbance value (OD) of each well was measured at $490 \mathrm{~nm}$. Experiments were carried out three times.

Colony formation assay. Cells were plated in 6-well culture plates at 200 cells/well. After incubation for 13 days at $37^{\circ} \mathrm{C}$, cells were washed twice with PBS and stained with the Giemsa solution. The number of colonies containing $\geq 50$ cells was counted under a microscope. The colony formation efficiency was calculated as (number of colonies/number of cells inoculated) $\times 100 \%$.

Cell-cycle analysis. For cell-cycle analysis, cells were seeded on $10 \mathrm{~cm}$ diameter plates in RPMI-1640 containing 10\% NBCS. After incubation for $48 \mathrm{~h}, \mathrm{a}$ total of $5 \times 10^{6}$ cells were harvested, rinsed with cold PBS, and fixed with $70 \%$ ice-cold ethanol for $48 \mathrm{~h}$ at $4^{\circ} \mathrm{C}$. Fixed cells were rinsed with cold PBS followed by incubation with PBS containing $10 \mu \mathrm{g} / \mathrm{ml}$ propidium iodide and $0.5 \mathrm{mg} / \mathrm{ml} \mathrm{RNase} \mathrm{A}$ for $30 \mathrm{~min}$ at $37^{\circ} \mathrm{C}$. The DNA content of labeled cells was acquired using FACS 
cytometry (BD Biosciences Inc., Franklin Lakes, NJ, USA). Each experiment was performed in triplicate.

Wound-healing assay. Cell migration was assessed using scratch-healing assays. Briefly, KB and Tca-8113 cells stably or transiently transfected with shRNA or siRNA and empty vectors were cultured in 6-well plates. When the cells grew to $90 \%$ confluence, three scratch wounds across each well were made using a $P-200$ pipette tip. Fresh medium supplemented with reduced (5\%) fetal bovine serum was added, and the wound-closing procedure was observed for $48 \mathrm{~h}$. Photographs were taken at 0 and $48 \mathrm{~h}$, respectively.

Invasion assay. For the invasion assay, $1 \times 10^{5}$ cells were seeded in $100 \mu \mathrm{l}$ RPMI-1640 media on the top of polyethylene terephthalate (PET) membranes coated with Matrigel TM $(1.5 \mathrm{mg} / \mathrm{ml}$, BD Biosciences $I n c$.) within transwell cell culture inserts (24-well inserts, $8 \mathrm{~mm}$ pore size; Corning Life Sciences, Corning, NY, USA). The bottom chamber was filled with $600 \mu \mathrm{l}$ RPMI-1640 media containing $20 \% \mathrm{FBS}$. The cells were incubated for $12 \mathrm{~h}$ at $37^{\circ} \mathrm{C}$ with $5 \% \mathrm{CO}_{2}$. Subsequently, the cells were fixed in $2.5 \%(\mathrm{v} / \mathrm{v})$ glutaraldehyde and stained with crystal violet. The invasive cells on the gel bottom were visualized under a microscope (Leica Inc., Wetzlar, Germany) and quantified by counting the number of cells in three randomly chosen fields at 200-fold magnification.

Solid-phase adhesion assay. The adhesion assay was performed using the tetrazolium-based colorimetric assay (MTT). Equal numbers of cells were seeded into 96-well plates that had been precoated with $1 \mathrm{mg} / \mathrm{ml}$ of fibronectin (FN) (Sigma Inc., Osterode am Harz, Germany). As a comparison, an equal number of cells were also seeded in plates coated with bovine serum albumin $(1 \% \mathrm{w} / \mathrm{v})$. After $1 \mathrm{~h}$, the plates were immersed into PBS containing $1 \mathrm{mM} \mathrm{MgCl} 2$ to remove non adherent cells. The number of adherent cells was then measured by MTT assay and read at $490 \mathrm{~nm}$. The OD values reflected the proportion of cells that adhered to the FN-coated 96-well plate. The rate of adhesion was calculated by the following equation: value of the $\mathrm{OD}$ of the experiment/value of the $\mathrm{OD}$ of the control $\times 100 \%$.

In vivo tumor growth assay. Cells were harvested by trypsinization, washed twice with cold serum-free medium, and resuspended with serum-free medium. To evaluate cancer growth in vivo, $2 \times 10^{6} \mathrm{~KB} / \mathrm{sh}-\mathrm{con}, \mathrm{KB} / \mathrm{sh}-\mathrm{FAP}-1$ and $\mathrm{KB} / \mathrm{sh}-\mathrm{FAP}-2$ cells were independently injected subcutaneously into the left back and right back of 11 nude mice. After injection, fluorescence emitted by cells was collected and imaged with a whole-body GFP imaging system (Lighttools, Encinitas, CA, USA). IPP5.0 software (Cybermetics, Silver Spring, MD, USA) was used for analysis of whole-body optical images, which visualized real-time tumor growth and tumor area.

In vivo metastasis assays. To evaluate the in vivo lung and liver metastatic potential of cancer cells, $5 \times 10^{6} \mathrm{~KB} / \mathrm{sh}$-con, KB/sh-FAP-1 and $\mathrm{KB} / \mathrm{sh}$-FAP-2 cells were injected into nude mice ( $n=5$ for each group) through the spleen, respectively. Whole-body optical images were visualized to monitor primary tumor growth and formation of metastatic lesions. Two months later, all mice were killed, individual organs were removed, and metastatic tissues were analyzed by $\mathrm{H} \& \mathrm{E}$ staining.

Immunohistochemistry. Examination of FAP expression in samples of OSCC and its control tissues by IHC has been previously described ${ }^{39,40}$ with FAP antibody $(1: 80)$ as previously described. The stained tissue sections were reviewed and scored independently by two pathologists blinded to the clinical parameters. The staining score standard has also been described. ${ }^{39,40}$ For statistical analysis of FAP expression in noncancerous tissues against OSCC tissues, staining scores of $0-4$ and 5-6 were respectively considered to be low and high expression.

Statistical analysis. SPSS 13.0 software (SPSS Inc., Chicago, IL, USA) and GraphPad software (GraphPad Software, Inc., La Jolla, CA, USA) were used to analyze all data for statistical significance. The Chi-Square test was applied to the examination of relationship between FAP expression levels and clinicopathological characteristics. Two-tailed Student's $t$-test was used for comparisons of two independent groups. One-way ANOVA was used to determine the differences between groups for all in vitro analyses. A $P$-value of $<0.05$ was considered as statistically significant.

\section{Conflict of Interest}

The authors declare no conflict of interest.

Acknowledgements. This study was supported by Guangdong Natural Science Funds (No. S2011010003852), The Science and Technology Planning Project of Guangdong Province (No. 2012B031800139), The Medical Scientific Research Foundation of Guangdong Province (No. A2012362), New Star Plan of Pearl River Science and Technology from Guangzhou City (No. 2011J2200009).

1. Markopoulos AK. Current aspects on oral squamous cell carcinoma. Open Dent J 2012; 6: $126-130$.

2. Jian SL, Hsieh HY, Liao CT et al. Galpha(1)(2) drives invasion of oral squamous cell carcinoma through up-regulation of proinflammatory cytokines. PLoS One 2013; 8: e66133.

3. Albuquerque R, Lopez-Lopez J, Mari-Roig A et al. Oral tongue squamous cell carcinoma (OTSCC): alcohol and tobacco consumption versus non-consumption. A study in a Portuguese population. Braz Dent J 2011; 22: 517-521.

4. Chaudhary A, Pandya S, Singh M et al. Identification of high-risk human papillomavirus- 16 and -18 infections by multiplex PCR and their expression in oral submucous fibrosis and oral squamous cell carcinoma. Head Neck Oncol 2013; 5 : 4.

5. Hsieh $\mathrm{CH}$, Chang JW, Hsieh JJ et al. Epidermal growth factor receptor mutations in patients with oral cavity cancer in a betel nut chewing-prevalent area. Head Neck2011; 33: 1758-1764.

6. Reis PP, Tomenson M, Cervigne NK et al. Programmed cell death 4 loss increases tumor cell invasion and is regulated by miR-21 in oral squamous cell carcinoma. Mol Cancer 2010; 9: 238.

7. Li C, Fan J, Song $X$ et al. Expression of angiopoietin-2 and vascular endothelial growth factor receptor-3 correlates with lymphangiogenesis and angiogenesis and affects survival of oral squamous cell carcinoma. PLoS One 2013; 8: e75388.

8. Yang W, Han W, Ye S et al. Fibroblast activation protein-alpha promotes ovarian cancer cell proliferation and invasion via extracellular and intracellular signaling mechanisms. Exp Mol Pathol 2013; 95: 105-110.

9. Lee HO, Mullins SR, Franco-Barraza J et al. FAP-overexpressing fibroblasts produce an extracellular matrix that enhances invasive velocity and directionality of pancreatic cancer cells. BMC Cancer 2011; 11: 245.

10. Kelly $\mathrm{T}$, Kechelava S, Rozypal TL et al. Seprase, a membrane-bound protease, is overexpressed by invasive ductal carcinoma cells of human breast cancers. Mod Pathol 1998; 11: 855-863.

11. Shi $M, Y u D H, C h e n ~ Y$ et al. Expression of fibroblast activation protein in human pancreatic adenocarcinoma and its clinicopathological significance. World J Gastroenterol 2012; 18: 840-846.

12. Mori $Y$, Kono K, Matsumoto $Y$ et al. The expression of a type II transmembrane serine protease (Seprase) in human gastric carcinoma. Oncology 2004; 67: 411-419.

13. Iwasa S, Okada K, Chen WT et al. 'Increased expression of seprase, a membrane-type serine protease, is associated with lymph node metastasis in human colorectal cancer'. Cancer Lett 2005; 227: 229-236.

14. Jin $\mathrm{X}$, Iwasa $\mathrm{S}$, Okada $\mathrm{K}$ et al. Expression patterns of seprase, a membrane serine protease, in cervical carcinoma and cervical intraepithelial neoplasm. Anticancer Res 2003; 23: 3195-3198.

15. Peyton SR, Ghajar CM, Khatiwala CB et al. The emergence of ECM mechanics and cytoskeletal tension as important regulators of cell function. Cell Biochem Biophys 2007; 47: 300-320

16. Turley EA, Veiseh M, Radisky DC et al. Mechanisms of disease: epithelial-mesenchymal transition-does cellular plasticity fuel neoplastic progression? Nat Clin Pract Oncol 2008; 5: 280-290.

17. Sarrio D, Rodriguez-Pinilla SM, Hardisson D et al. Epithelial-mesenchymal transition in breast cancer relates to the basal-like phenotype. Cancer Res 2008; 68: 989-997.

18. Cross DA, Alessi DR, Cohen $P$ et al. Inhibition of glycogen synthase kinase- 3 by insulin mediated by protein kinase B. Nature 1995; 378: 785-789.

19. Cohen P, Frame S. The renaissance of GSK3. Nat Rev Mol Cell Biol 2001; 2: 769-776.

20. Hua X, Yu L, Huang $X$ et al. Expression and role of fibroblast activation protein-alpha in microinvasive breast carcinoma. Diagn Pathol 2011; 6: 111.

21. Wikberg ML, Edin S, Lundberg IV et al. High intratumoral expression of fibroblast activation protein (FAP) in colon cancer is associated with poorer patient prognosis. Tumour Biol 2013; 34: 1013-1020.

22. Cohen SJ, Alpaugh RK, Palazzo I et al. Fibroblast activation protein and its relationship to clinical outcome in pancreatic adenocarcinoma. Pancreas 2008; 37: 154-158.

23. Liao Y, Ni Y, He R et al. Clinical implications of fibroblast activation protein-alpha in nonsmall cell lung cancer after curative resection: a new predictor for prognosis. J Cancer Res Clin Oncol 2013; 139: 1523-1528.

24. Huang L, Wang HY, Li JD et al. KPNA2 promotes cell proliferation and tumorigenicity in epithelial ovarian carcinoma through upregulation of c-Myc and downregulation of FOXO3a. Cell Death Dis 2013; 4: e745. 
25. Romano S, Staibano S, Greco A et al. FK506 binding protein 51 positively regulates melanoma stemness and metastatic potential. Cell Death Dis 2013; 4: e578.

26. Hanai JI, Doro N, Seth P et al. ATP citrate lyase knockdown impacts cancer stem cells in vitro. Cell Death Dis 2013; 4: e696.

27. Saxena M, Stephens MA, Pathak $\mathrm{H}$ et al. Transcription factors that mediate epithelialmesenchymal transition lead to multidrug resistance by upregulating $A B C$ transporters Cell Death Dis 2011; 2: e179.

28. He L, Zhou X, Qu C et al. Musashi2 predicts poor prognosis and invasion in hepatocellular carcinoma by driving epithelial-mesenchymal transition. J Cell Mol Med 2014; 18: 49-58.

29. Zhao XL, Sun $\mathrm{T}$, Che $\mathrm{N}$ et al. Promotion of hepatocellular carcinoma metastasis through matrix metalloproteinase activation by epithelial-mesenchymal transition regulator Twist1 $J$ Cell Mol Med 2011; 15: 691-700.

30. Van Tubergen EA, Banerjee R, Liu M et al. Inactivation or loss of TTP promotes invasion in head and neck cancer via transcript stabilization and secretion of MMP9, MMP2, and IL-6. Clin Cancer Res 2013; 19: 1169-1179.

31. Liu J, van Mil A, Aguor EN et al. MiR-155 inhibits cell migration of human cardiomyocyte progenitor cells (hCMPCs) via targeting of MMP-16.J. Cell Mol Med 2012; 16: 2379-2386.

32. Song G, Ouyang G, Mao $Y$ et al. Osteopontin promotes gastric cancer metastasis by augmenting cell survival and invasion through Akt-mediated HIF-1alpha up-regulation and MMP9 activation. J Cell Mol Med 2009; 13: 1706-1718.

33. Bullock MD, Pickard KM, Nielsen BS et al. Pleiotropic actions of miR-21 highlight the critica role of deregulated stromal microRNAs during colorectal cancer progression. Cell Death Dis 2013; 4: e684.

34. Wen W, Ding J, Sun W et al. Cyclin G1-mediated epithelial-mesenchymal transition via phosphoinositide 3-kinase/Akt signaling facilitates liver cancer progression. Hepatology 2012; 55: 1787-1798.

35. Ye Y, Xiao $\mathrm{Y}$, Wang $\mathrm{W}$ et al. ERalpha signaling through slug regulates $\mathrm{E}$-cadherin and EMT. Oncogene 2010; 29: 1451-1462.
36. Han L, Peng B, Ma Q et al. Indometacin ameliorates high glucose-induced proliferation and invasion via modulation of e-cadherin in pancreatic cancer cells. Curr Med Chem 2013; 20: 4142-4152.

37. Dong-Dong L, Xi-Ran Z, Xiang-Rong C. Expression and significance of new tumor suppressor gene PTEN in primary liver cancer. J Cell Mol Med 2003; 7: 67-71.

38. Luo $\mathrm{H}$, Yang $\mathrm{Y}$, Duan J et al. PTEN-regulated AKT/FoxO3a/Bim signaling contributes to reactive oxygen species-mediated apoptosis in selenite-treated colorectal cancer cells. Cell Death Dis 2013; 4: e481.

39. Liu Z, Luo W, Zhou Y et al. Potential tumor suppressor NESG1 as an unfavorable prognosis factor in nasopharyngeal carcinoma. PLOS One 2011; 6: e27887.

40. $\mathrm{Yu} \mathrm{X}$, Zhen $\mathrm{Y}$, Yang $\mathrm{H}$ et al. Loss of connective tissue growth factor as an unfavorable prognosis factor activates miR-18b by PI3K/AKT/C-Jun and C-Myc and promotes cell growth in nasopharyngeal carcinoma. Cell Death Dis 2013; 4: e634.

(c) (1) $(9)$ Cell Death and Disease is an open-access journal published by Nature Publishing Group. This work is licensed under a Creative Commons Attribution-NonCommercialNoDerivs 3.0 Unported License. The images or other third party material in this article are included in the article's Creative Commons license, unless indicated otherwise in the credit line; if the material is not included under the Creative Commons license, users will need to obtain permission from the license holder to reproduce the material. To view a copy of this license, visit http://creativecommons.org/licenses/ by-nc-nd/3.0/

Supplementary Information accompanies this paper on Cell Death and Disease website (http://www.nature.com/cddis) 